\title{
Ultrastructural analysis of transitional endoplasmic reticulum and pre-Golgi intermediates: a highway for cars and trucks
}

\begin{abstract}
Cargo selection and export from the endoplasmic reticulum occurs at specialized sites in cells. Export complexes consist of transitional elements of the endoplasmic reticulum and pre-Golgi intermediates. It is generally assumed that 60 to $80 \mathrm{~nm}$ initially COPIIcoated vesicles derived from the transitional endoplasmic reticulum are the main carriers for transport of cargo to the Golgi apparatus. We have analyzed on serial ultrathin sections the transitional endoplasmic reticulum and preGolgi intermediates of beta cells of islets of Langerhans in mouse pancreas. In addition to Golgi-associated complexes, others were observed in the periphery of the cells or close to the nuclear envelope. Upon threedimensional reconstruction, non-coated ribosome-free tubules with an average diameter of $115 \mathrm{~nm}$ (range 60$195 \mathrm{~nm}$ ) and a length of up to $500 \mathrm{~nm}$ were detected in the pre-Golgi intermediates in addition to small vesiculotubular elements. Furthermore, evidence was found that the large tubular elements may directly arise from transitional elements of the endoplasmic reticulum. In a given cell, pre-Golgi intermediates were found to be composed solely of small vesiculo-tubular elements or additionally of tubules or solely of tubules. Immunogold labeling for proinsulin indicated that the large tubular elements contained cargo and thus appear to take part in ER-to-Golgi transport.
\end{abstract}

Keywords Transitional ER · Pre-Golgi intermediates · Tubules $\cdot$ Electron microscopy $\cdot 3$-D reconstruction

Presented at the 43rd Symposium of the Society for Histochemistry, Vienna, Austria, 27-29 September 2001

J.-Y. Fan · J. Roth $(-$ C. Zuber

Division of Cell and Molecular Pathology,

Department of Pathology,

University of Zurich,

Schmelzbergstrasse 12, 8091 Zurich, Switzerland

e-mail: juergen.roth@usz.ch

Tel.: +41-1-2555090

Fax: +41-1-2554407

\section{Introduction}

In their pioneering studies, Palade and coworkers established that protein transport from the endoplasmic reticulum (ER) to the Golgi apparatus occurred at specialized sites of the ER, the transitional elements, and involved vesicular carriers (Palade 1975). The transitional elements represent an ER subdomain continuous with the rough ER which is characteristically devoid of ribosomes and exhibits buds which have a COPII coat. Recent studies have shown that the transitional ER elements represent long-lived, relatively immobile structures (Hammond and Glick 2000; Stephens et al. 2000). Closely associated with the transitional elements exist clusters of smooth membrane structures referred to as intermediate compartment, ERGIC-53, vesiculo-tubular clusters or pre-Golgi intermediates (Bannykh et al. 1996; Hauri et al. 2000; Saraste and Kuismanen 1992). The pre-Golgi intermediates represent dynamic structures located between the ER and the cis Golgi apparatus, at multiple sites in the periphery of the cell and close to the nuclear envelope (Lippincott-Schwartz 2001; Lippincott-Schwartz et al. 2000; Presley et al. 1997; Scales et al. 1997; Stephens et al. 2000). A most detailed and quantitative electron microscopic analysis of serial thin sections has established the spatial relationship between the budding sites of the transitional elements of the ER and the vesiculotubular elements at these three cellular sites (Bannykh et al. 1996). Along transitional ER elements, active budding zones, which also included COPII-coated tubular projections of the ER membrane generally shorter than $150 \mathrm{~nm}$, were found to surround discrete vesiculo-tubular clusters. These clusters comprised vesicles $60-80 \mathrm{~nm}$ in diameter, short tubules, and pleomorphic elements.

Although it is undisputed that the transitional elements and pre-Golgi intermediates are functionally close partners in anterograde cargo traffic, the structure of the carriers is still a matter of dispute. The prevailing notion is that the COPII-coated buds of the transitional elements of the ER, into which anterograde cargo is actively sorted, probably through the action of cargo receptors (Belden 
and Barlowe 1996; Blum et al. 1996; Fiedler and Rothman 1997; Fiedler et al. 1996; Muniz et al. 2000), give rise to 60 to $80 \mathrm{~nm}$ COPII-coated vesicles (Antonny and Schekman 2001; Aridor et al. 2001; Bednarek et al. 1995; Kaiser and Ferro-Novick 1998; Klumperman 2000; Kuehn and Schekman 1997). It was reported that COPIIcoated vesicles fuse with each other or neighboring vesicular-tubular clusters to form larger carriers (Bannykh et al. 1996; Horstmann et al. 2002).

The view that small initially COPII-coated vesicles represent the sole cargo carrier has been criticized for several reasons. One is that large macromolecular cargo such as $300 \mathrm{~nm}$ long trimers of procollagen I, which are formed in the ER, would not fit easily into 60 to $80 \mathrm{~nm}$ COPII-coated vesicles (Bonfanti et al. 1998). Electron microscopic studies have provided evidence that larger non-COPII-coated elements exist in pre-Golgi intermediates (Ladinsky et al. 1999; Lahtinen et al. 1992; Saraste and Svensson 1991; Sesso et al. 1994), in particular under conditions of temperature-induced ER-to-Golgi transport blockade (Palokangas et al. 1998; Saraste and Kuismanen 1984; Stinchcombe et al. 1995), but their mode of formation remains to be established. Furthermore, observation of green fluorescent protein-tagged cargo by timelapse light microscopy in living cells has provided evidence that pre-Golgi intermediates formed large tubular elements that translocated in a microtubule-dependent manner to the Golgi apparatus (Lippincott-Schwartz 2001; Presley et al. 1997; Scales et al. 1997).

The present study was performed to obtain 3-D information from serial ultrathin sections of transitional ER and pre-Golgi intermediates in pancreatic beta cells with emphasis on the relationship of transitional ER and structures different from COPII-coated vesicles. We provide electron microscopic evidence that in addition to classic COPII buds and vesicles, large non-coated tubular elements arise from transitional elements of the ER and contain secretory cargo.

\section{Materials and methods}

\section{Animals}

C57BL/6 J mice were used in this study and they had free access to food and drinking water.

\section{Electron microscopy and serial sectioning}

Pancreas from C57BL/6 J mice was fixed by perfusion from the left cardiac ventricle with $3 \%$ glutaraldehyde in isotonic phosphatebuffered saline (PBS; 0.1 M phosphate buffer, $\mathrm{pH} 7.2,0.15 \mathrm{M}$ $\mathrm{NaCl})$ and small $\left(\leq 1 \mathrm{~mm}^{3}\right)$ pieces were postfixed in $1 \%$ buffered $\mathrm{OsO}_{4}$ followed by Epon embedding according to standard protocol.

Epon blocks containing islets of Langerhans were identified and ribbons of 15-30 consecutive sections of a nominal thickness of $70 \mathrm{~nm}$ were cut with a diamond knife (Diatome, Biel, Switzerland) on a Reichert ultramicrotome Ultracut S. The ribbons of serial sections were transferred to single slot grids coated with a Formvar/ carbon film. Sections were counterstained with $3 \%$ aqueous uranyl acetate $(20 \mathrm{~min})$ and lead acetate $(5 \mathrm{~min})$ and investigated with a
Zeiss EM 910 electron microscope (Zeiss, Oberkochen, Germany) equipped with a position memory. Cellular regions of interest were followed in consecutive serial sections and photographed on $70 \mathrm{~mm}$ sheet films at an original magnification of $\times 20,000$. Negatives were scanned using Photoshop software. Images were overlaid to evaluate structure relationships. Data acquisition was performed by tracing the contours of the transitional elements and of the preGolgi intermediates as well as Golgi cisternal stack from digitized micrographs using Photoshop software. Coalignment was based on the position of secretory granules and/or mitochondria.

\section{Immunoelectron microscopy}

Ultrathin Epon sections from glutaraldehyde-osmium tetroxidefixed tissue mounted on nickel grids were placed on droplets of freshly prepared $1 \%$ aqueous periodic acid for 4-6 min at ambient temperature and thereafter thoroughly rinsed for $30 \mathrm{~min}$ by passing them over a series of droplets of distilled water (Roth et al. 1985, 2000). Sections were then conditioned with PBS containing $1 \%$ BSA, $0.01 \%$ Triton $\mathrm{X}-100$, and $0.01 \%$ Tween 20 for $10 \mathrm{~min}$ at ambient temperature and transferred to droplets of guinea pig antirat C-peptide antibodies for $2 \mathrm{~h}$ at ambient temperature. Following rinses with buffer, grids were incubated with $8 \mathrm{~nm}$ protein A-gold complexes diluted to an absorbance of 0.06 in conditioning buffer for $1 \mathrm{~h}$. Finally, grids with the attached thin sections were rinsed in PBS, fixed with $2 \%$ glutaraldehyde in PBS for 10-20 min, rinsed with PBS and distilled water, and contrasted with uranyl and lead acetate as described above. Control incubations included replacement of the anti-C-peptide antibody with an unrelated polyclonal antibody raised in rabbit (anti-chicken $\mathrm{IgG}$ ) and by omission of the primary antibody.

\section{Results}

Figure 1A contains a sequence of six consecutive serial sections illustrating the classic appearance of transitional ER with COPII buds and of pre-Golgi intermediates composed of 60 to $80 \mathrm{~nm}$ vesicles and single short tubules in a pancreatic beta cell of an islet of Langerhans. The vesicles often exhibited a coat and the short tubules had a dense coat at their tips (Figs. 1,2), as previously reported by many other investigators. A systematic analysis of series of consecutive serial ultrathin sections from many pancreatic beta cells revealed a surprising, hitherto not reported structural variability of transitional ER and pre-

Fig. 1A, B Consecutive serial ultrathin sections from pancreatic beta cells. A A transitional element of the rough ER (denoted by shades of yellow to ochre from section \#1 to \#5), a pre-Golgi intermediate composed of 60 to $80 \mathrm{~nm}$ vesicles and short tubules (denoted by shades of green with increasing intensity from section \#1 to \#5), and a Golgi cisternal stack (denoted by shades of blue with increasing intensity from section \#1 to \#5) are shown. Asterisk in sections $\# 1$ to $\# 5$ denotes an insulin secretory granule used for coalignment. The three-dimensional reconstruction from the membrane contours shows the clustered arrangement of the vesiculotubular elements into which short tubular extension of transitional elements with coated tips enter. B Consecutive serial sections with a transitional element of ER $(T E)$ and a pre-Golgi intermediate ( $p G I$ ) facing toward the cis side of the Golgi apparatus $(G)$. The pGI consists of several large circular elements which can be followed through sections $\# 1$ to $\# 5$ and numerous small vesicles some of which have a coat (arrow in sections \#2 and \#3). One circular structure has a coated bud (arrowhead in sections \#2 and \#3). $N$ Nucleus. Bars $0.26 \mu \mathrm{m}$ in $\mathbf{A} ; 0.3 \mu \mathrm{m}$ in $\mathbf{B}$ 

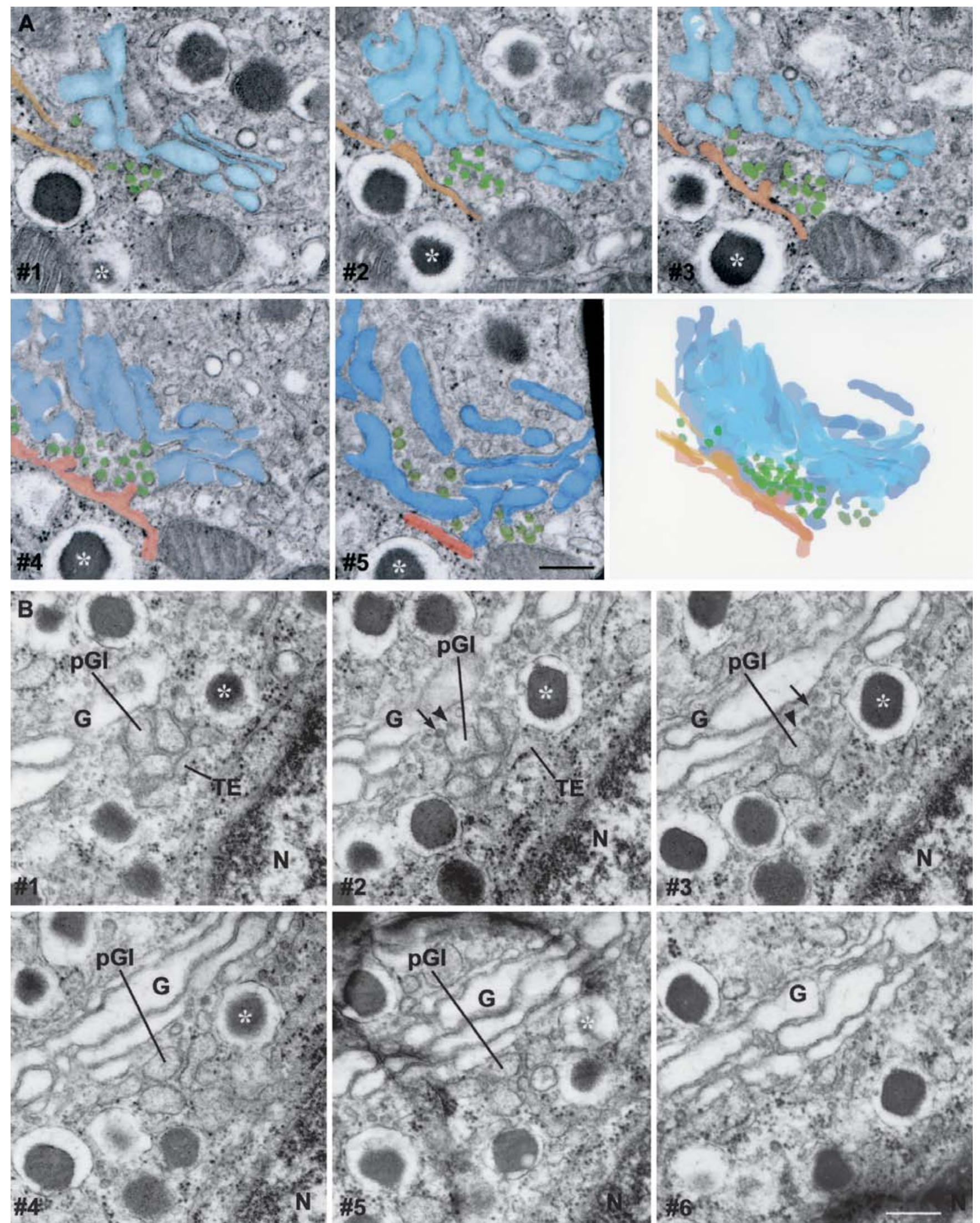

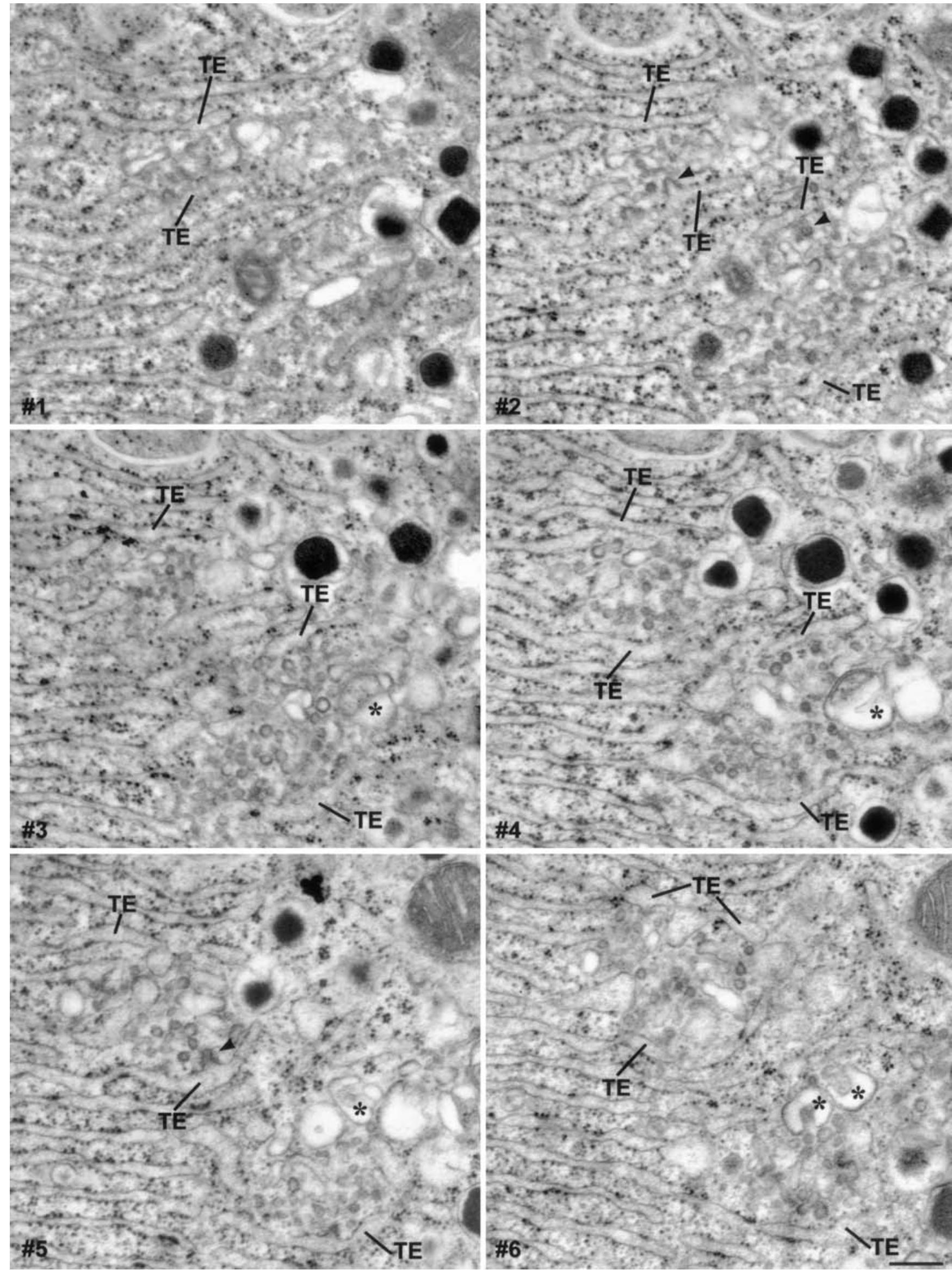

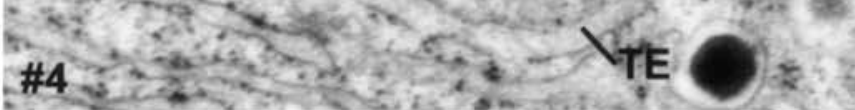

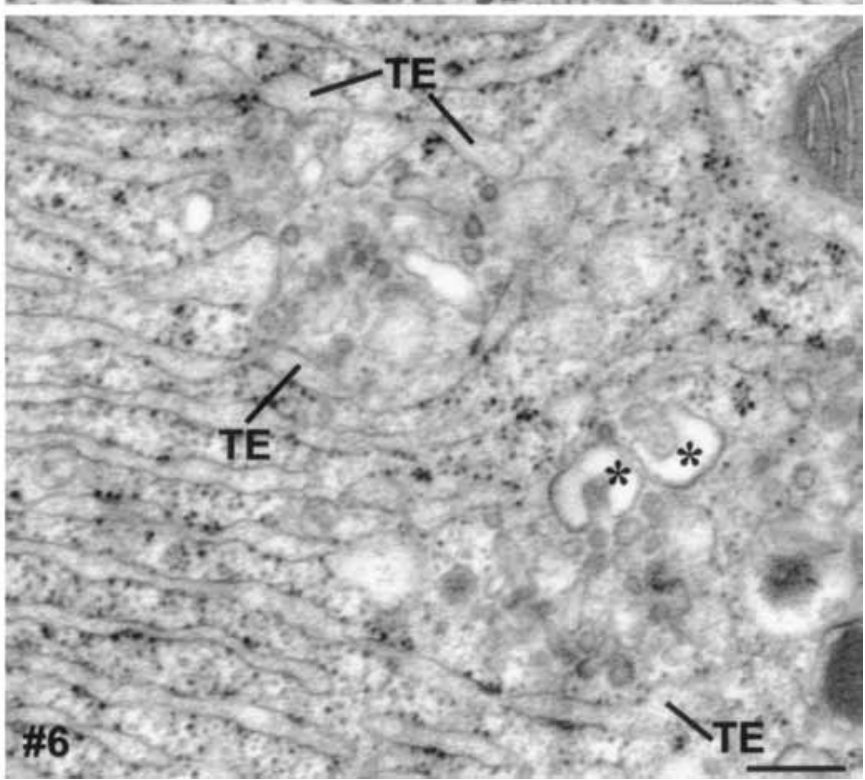



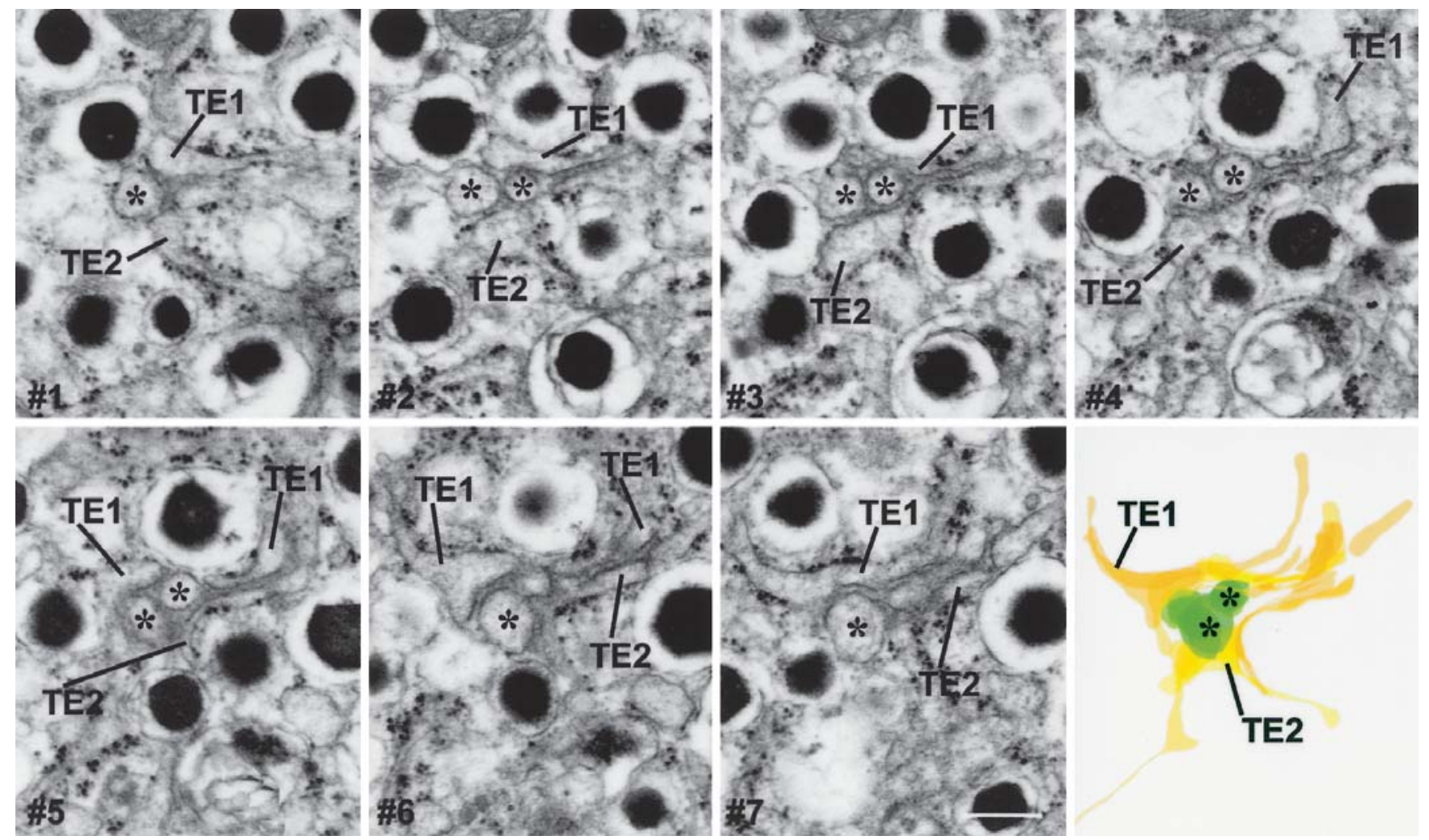

Fig. 3 A small peripheral pre-Golgi intermediate composed of two circular elements (asterisks) of which one can be followed through all seven serial sections and the other through four serial sections. They are surrounded by two transitional elements of the ER (TE1 and TE2). The three-dimensional reconstruction from the contours

of the transitional elements TE1 and TE2 (shades of yellow in increasing intensity from section \#1 to \#7) and the two circular elements (shades of green in increasing intensity from section \#1 to \#7) demonstrates the tubular nature of the pre-Golgi intermediate. Bar $0.28 \mu \mathrm{m}$

Golgi intermediates. Figure 1B shows another Golgi apparatus-associated pre-Golgi intermediate which is not only composed of small, often coated vesicles, but additionally contains several circular elements which could be followed through five of the presented six serial sections. Thus, the circular elements are cross-sectioned tubules with a length of $>350 \mathrm{~nm}$ (based on $70 \mathrm{~nm}$ section thickness). Such tubules sometimes exhibited coated buds (sections \#2 and \#3 in Fig. 1B). Similar observations were made by analyzing serial sections from transitional elements and pre-Golgi intermediates present in the periphery of the cells, not associated with the Golgi apparatus. As shown in Fig. 2, such complexes although discrete were often close to each other. This series of six serial sections out of a larger series furthermore illustrates the morphological complexity of the pre-Golgi intermediates. Besides numerous 60 to $80 \mathrm{~nm}$ coated and noncoated vesicles and short tubular elements, larger circular

Fig. 2 A series of six consecutive sections showing transitional elements of the ER (TE) which exhibit coated buds (for instance see arrowheads in sections \#2 and \#5) and surround two peripheral preGolgi intermediates composed of vesiculo-tubular elements, pleomorphic elements (asterisks in sections \#3 to \#6), and several larger circular elements. Transitional ER is often distended (see sections \#3 and \#5). Bar $0.28 \mu \mathrm{m}$

elements and pleomorphic elements existed. Figure 3 shows a series of seven serial sections through another peripheral pre-Golgi intermediate surrounded by two transitional elements of the ER. The small pre-Golgi intermediate consisted of only two circular elements which represented cross-sectioned tubules. This discreet structure will be easily missed in random single sections. Such tubules present in Golgi-associated and peripheral pre-Golgi intermediates had an average diameter of $115 \mathrm{~nm}$ (range 60-195 nm) and a length of up to $500 \mathrm{~nm}$. Based on the analysis of series of consecutive ultrathin sections, these tubules were always closely related but usually discrete from transitional elements of the ER. Figure 4 shows serial sections from a large Golgiassociated complex and two smaller ones in its neighborhood. Transitional elements exhibiting typical COPIIcoated structures were obvious. Remarkably, one was associated with a mitochondrion (sections \#4 and \#5). One transitional element (TE1) could be followed through six serial sections. In addition to several coated buds, it formed a long, non-coated tubular structure (open arrow in section \#3) separated by a distinct constriction (arrow in section \#3). Another transitional element (TE2), besides exhibiting a coated bud, showed two distinct constrictions (section \#5) giving raise to two circular elements which in the two adjacent serial sections 


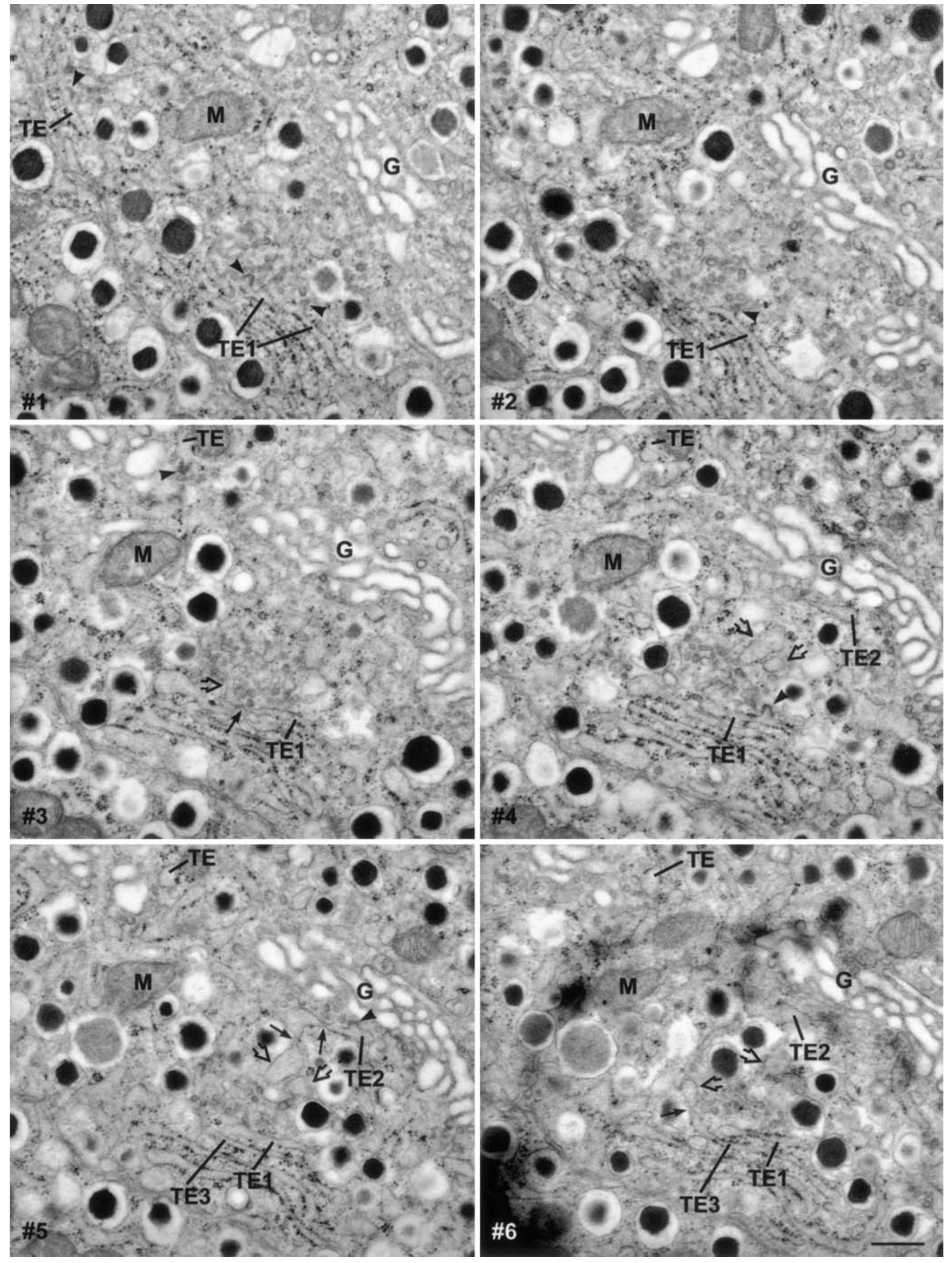


Fig. 5A, B Immunogold labeling for C-peptide with the protein A-gold technique. A PreGolgi intermediate $(p G I)$ adjacent to the nucleus $(N)$ and $\mathbf{B}$ peripheral pre-Golgi intermediate are labeled. Bars $0.32 \mu \mathrm{m}$ in $\mathbf{A} ; 0.25 \mu \mathrm{m}$ in $\mathbf{B}$
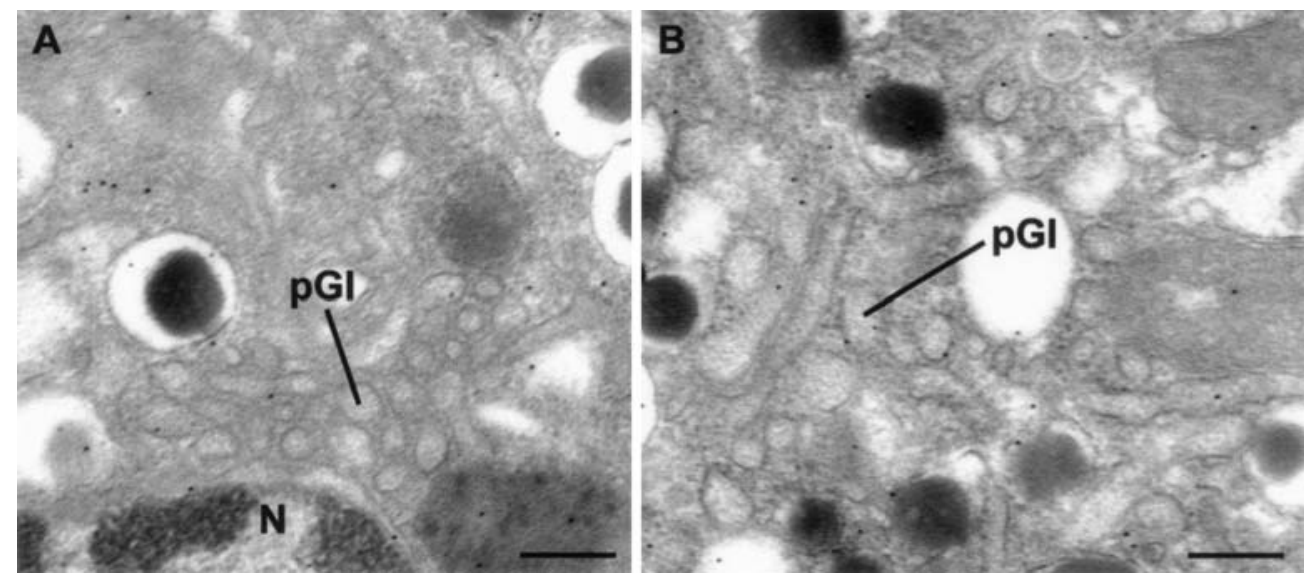

appeared as discrete elements. Likewise, transitional element TE3 showed a distinct constriction. Upon closer inspection of these constrictions, fine string-like densities were obvious. Figure 5 shows immunogold labeling with an anti-C-peptide antibody over circular (i.e., tubular) elements of pre-Golgi intermediates. Based on the known topography of proinsulin-insulin conversion in immature secretory granules (Orci et al. 1985, 1987), this immunolabeling is indicative of proinsulin.

\section{Discussion}

We have performed a serial thin section analysis of transitional elements of the ER and pre-Golgi intermediates in a highly specialized, regulated secretory cell type, the insulin-producing beta cells of islets of Langerhans. The ensemble of the two investigated structures represents ER export complexes (Bannykh and Balch 1997; Bannykh et al. 1996). Although it is assumed that in regulated secretory cell types, ER export complexes predominantly exist in juxtaposition of the cis side of the Golgi apparatus, studies performed on pancreatic acinar cells (Lahtinen et al. 1992), hepatocytes (Zuber et al.

Fig. 4 A series of six consecutive serial sections from a large Golgi-associated pre-Golgi intermediate (center of the micrographs) and two other pre-Golgi intermediates (upper left hand corner of micrographs) with their transitional elements of ER (TE). TE1 can be followed through all sections and has several coated buds (arrowheads in sections \#1, \#2, and \#4). In section \#3, TE1 shows a distinct constriction (arrow) followed by a long, ribosomefree non-coated tubular element (open arrow). In addition to numerous small vesicles, the pre-Golgi intermediate in the center of the micrograph contains seemingly isolated large non-coated circular elements (open arrows in section \#4 and upper open arrow in section \#6) of which one is actually luminally continuous with TE2 in section \#5. TE2 in section \#5 has a coated bud but also exhibits two distinct constrictions (arrows) followed by distended non-coated portions (the distal one is marked by an open arrow). Likewise, TE3 in section \#6 has a distinct constriction (arrow) distally followed by a distended non-coated portion (open arrow). Note the close association of a transitional element exhibiting a coated bud with a mitochondrion (TE and arrowhead in upper part of section \#3). $M$ Mitochondrion, $G$ Golgi apparatus. Bar $0.37 \mu \mathrm{m}$
2001), and pancreatic beta cells (this study) demonstrated the presence of numerous such ER export complexes in the periphery of the cells.

Our study was performed on a professional secretory cell type present in its natural tissue environment in contrast to other studies on different permanent cell lines maintained in culture. The systematic analysis of transitional ER and pre-Golgi intermediates in series of consecutive ultrathin sections confirmed data of another such serial sectioning study on cultured normal rat kidney (NRK) and rat basophilic leukemia (RBL) cells (Bannykh et al. 1996) but in addition revealed novel structural aspects which are potentially of importance for ER-toGolgi transport processes. We observed transitional ER which in addition to characteristic coated buds showed distinct constrictions. Distal of such constrictions, circular non-coated elements existed. Furthermore, non-coated circular elements not luminally continuous with but adjacent to transitional ER were observed as constituents of pre-Golgi intermediates. Our findings suggest that they pinch-off from transitional ER and do not form by fusion of smaller vesicles. Very rarely, coated buds were observed on the circular elements which most probably represent buds which will give rise to vesicles. The first unequivocal evidence for a distinct compositional and structural heterogeneity of the pre-Golgi intermediates came from analytical cell fractionation of NRK cells (Ying et al. 2000). The sedimentation profile of p58containing pre-Golgi intermediates showed the existence of two main subpopulations of particles: a light fraction enriched in small vesicles/tubules and a heavy fraction containing large-sized membranous elements. Interestingly, the latter subpopulation of pre-Golgi intermediate elements was reported to be largely free of coat components and to be also less abundant than the subpopulation of small-sized vesiculo-tubular elements. It is tempting to speculate that they correspond to the transitional ERderived elements observed in the present study in a regulated secretory cell type.

Our serial sectioning analysis demonstrated that the circular elements seen in a single section were tubules of varying diameter and a length of up to $500 \mathrm{~nm}$. These 
tubules may correspond to the large often tubular preGolgi intermediates observed by time-lapse light microscopy that were translocated to the Golgi apparatus (Lippincott-Schwartz 2001; Presley et al. 1997; Scales et al. 1997). The sole evidence we have at present that the tubules represent cargo carriers is the demonstration of proinsulin. Based on their size, they potentially could be carriers for large macromolecules synthesized by other cell types, a proposal also made by Ying et al. (2000) based on their analytical cell fractionation study. We have evidence from serial sectioning that tubular elements of similar dimensions but numerically less abundant exist in pre-Golgi intermediates of cultured $\mathrm{CHO}$ cells and clone9 hepatocytes (manuscript in preparation).

In addition to the structural heterogeneity of a given pre-Golgi intermediate, we found structural heterogeneity between pre-Golgi intermediates in a given cell which only became obvious through the systematic analysis by serial sectioning. Pre-Golgi intermediates, whether or not associated with the Golgi apparatus, were composed solely of small vesiculo-tubular elements or additionally of tubules and pleomorphic elements. On the other hand, we observed small-sized peripheral pre-Golgi intermediates solely composed of tubules which in single random sections would easily escape their detection. Our static electron microscopic analysis does not permit conclusions as to whether structurally different pre-Golgi intermediates truly exist or if they reflect different functional states.

Note added in proof The formation of large saccular carriers by direct en bloc protusion from ER domains in the vicinity of COPIIcoated exit sites was recently reported. These carriers were shown to contain both large and small cargo such as procollagen I and VSV G protein, respectively. (Mironov AA et al. 2003: ER-toGolgi carriers arise through direct en bloc protusion and multistage maturation of specialized ER exit domains. Dev Cell 5:583-594)

Acknowledgements We are grateful to Bruno Guhl for skilled technical assistance, N. Wey for help in preparing the photographs, and Antoinette Schumacher for help in preparing the manuscript. This work was supported by the Swiss National Science Foundation and the Canton of Zurich.

\section{References}

Antonny B, Schekman R (2001) ER export: public transportation by the COPII coach. Curr Opin Cell Biol 13:438-443

Aridor M, Fish KN, Bannykh S, Weissman J, Roberts TH, Lippincott-Schwartz J, Balch WE (2001) The Sar1 GTPase coordinates biosynthetic cargo selection with endoplasmic reticulum export site assembly. J Cell Biol 152:213-229

Bannykh SI, Balch WE (1997) Membrane dynamics at the endoplasmic reticulum Golgi interface. J Cell Biol 138:1-4

Bannykh SI, Rowe T, Balch WE (1996) The organization of endoplasmic reticulum export complexes. J Cell Biol 135:1935

Bednarek SY, Ravazzola M, Hosobuchi M, Amherdt M, Perrelet A, Schekman R, Orci L (1995) COPI- and COPII-coated vesicles bud directly from the endoplasmic reticulum in yeast. Cell 83:1183-1196

Belden WJ, Barlowe C (1996) Erv25p, a component of COPIIcoated vesicles, forms a complex with emp $24 p$ that is required for efficient endoplasmic reticulum to Golgi transport. J Biol Chem 271:26939-26946

Blum R, Feick P, Puype M, Vandekerckhove J, Klengel R, Nastainczyk W, Schulz I (1996) Tmp21 and p24A, two type I proteins enriched in pancreatic microsomal membranes, are members of a protein family involved in vesicular trafficking. J Biol Chem 271:17183-17189

Bonfanti L, Mironov AA, Martinez-Menarguez JA, Martella O, Fusella A, Baldassarre M, Buccione R, Geuze HJ, Mironov AA, Luini A (1998) Procollagen traverses the Golgi stack without leaving the lumen of cisternae: evidence for cisternal maturation. Cell 95:993-1003

Fiedler K, Rothman JE (1997) Sorting determinants in the transmembrane domain of p24 proteins. J Biol Chem 272:24739-24742

Fiedler K, Veit M, Stamnes MA, Rothman JE (1996) Bimodal interaction of coatomer with the p24 family of putative cargo receptors. Science 273:1396-1399

Hammond AT, Glick BS (2000) Dynamics of transitional endoplasmic reticulum sites in vertebrate cells. Mol Biol Cell 11:3013-3030

Hauri HP, Kappeler F, Andersson H, Appenzeller C (2000) ERGIC-53 and traffic in the secretory pathway. J Cell Sci 113:587-596

Horstmann H, Ng CP, Tang BL, Hong WJ (2002) Ultrastructural characterization of endoplasmic reticulum-Golgi transport containers (EGTC). J Cell Sci 115:4263-4273

Kaiser C, Ferro-Novick S (1998) Transport from the endoplasmic reticulum to the Golgi. Curr Opin Cell Biol 10:477-482

Klumperman J (2000) Transport between ER and Golgi. Curr Opin Cell Biol 12:445-449

Kuehn MJ, Schekman R (1997) COPII and secretory cargo capture into transport vesicles. Curr Opin Cell Biol 9:477-483

Ladinsky MS, Mastronarde DN, McIntosh JR, Howell KE, Staehelin LA (1999) Golgi structure in three dimensions: functional insights from the normal rat kidney cell. J Cell Biol 144:1135-1149

Lahtinen U, Dahllof B, Saraste J (1992) Characterization of a 58$\mathrm{kDa}$ cis-Golgi protein in pancreatic exocrine cells. J Cell Sci 103:321-333

Lippincott-Schwartz J (2001) The secretory membrane system studied in real-time. Histochem Cell Biol 116:97-107

Lippincott-Schwartz J, Roberts TH, Hirschberg K (2000) Secretory protein trafficking and organelle dynamics in living cells. Annu Rev Cell Dev Biol 16:557-589

Muniz M, Nuoffer C, Hauri HP, Riezman H (2000) The Emp24 complex recruits a specific cargo molecule into endoplasmic reticulum-derived vesicles. J Cell Biol 148:925-930

Orci L, Ravazzola M, Amherdt M, Madsen O, Vassalli JD, Perrelet A (1985) Direct identification of prohormone conversion site in insulin-secreting cells. Cell 42:671-681

Orci L, Ravazzola M, Storch M-J, Anderson RGW, Vassalli J-D, Perrelet A (1987) Proteolytic maturation of insulin is a postGolgi event which occurs in acidifying clathrin-coated secretory vesicles. Cell 49:865-868

Palade G (1975) Intracellular aspects of the process of protein biosynthesis. Science 189:347-358

Palokangas H, Ying M, Vaananen K, Saraste J (1998) Retrograde transport from the pre-Golgi intermediate compartment and the Golgi complex is affected by the vacuolar $\mathrm{H}^{+}$-ATPase inhibitor bafilomycin A1. Mol Biol Cell 9:3561-3578

Presley J, Cole N, Schroer T, Hirschberg K, Zaal K, LippincottSchwartz J (1997) ER-to-Golgi transport visualized in living cells. Nature 389:81-85

Roth J, Kasper M, Heitz PU, Labat F (1985) What's new in light and electron microscopic immunocytochemistry? Application of the protein A-gold technique to routinely processed tissue. Pathol Res Pract 180:711-717

Roth J, Ziak M, Guhl B (2000) Non-heating antigen retrieval techniques for light and electron microscopic immunolabeling. In: Taylor CR, Shi S-R (eds) Antigen retrieval technique: a 
revolutionary approach to routine immunohistochemistry. Eaton, Natick, MA, pp 275-285

Saraste J, Kuismanen E (1984) Pre- and post-Golgi vacuoles operate in the transport of Semliki Forest virus membrane glycoproteins to the cell surface. Cell 38:535-549

Saraste J, Kuismanen E (1992) Pathways of protein sorting and membrane traffic between the rough endoplasmic reticulum and the Golgi complex. Semin Cell Biol 3:343-355

Saraste J, Svensson K (1991) Distribution of intermediate elements operating in ER to Golgi transport. J Cell Sci 100:415-430

Scales SJ, Pepperkok R, Kreis TE (1997) Visualization of ER-toGolgi transport in living cells reveals a sequential mode of action for COPII and COPI. Cell 90:1137-1148

Sesso A, Defaria FP, Iwamura ESM, Correa H (1994) A 3dimensional reconstruction study of the rough ER-Golgi interface in serial thin sections of the pancreatic acinar cell of the rat. J Cell Sci 107:517-528
Stephens DJ, LinMarq N, Pagano A, Pepperkok R, Paccaud JP (2000) COPI-coated ER-to-Golgi transport complexes segregate from COPII in close proximity to ER exit sites. J Cell Sci 113:2177-2185

Stinchcombe J, Nomoto H, Cutler D, Hopkins C (1995) Anterograde and retrograde traffic between the rough endoplasmic reticulum and the Golgi complex. J Cell Biol 131:1387-1401

Ying M, Flatmark T, Saraste J (2000) The p58-positive pre-Golgi intermediates consist of distinct subpopulations of particles that show differential binding of COPI and COPII coats and contain vacuolar H+-ATPase. J Cell Sci 113:3623-3638

Zuber C, Fan JY, Guhl B, Parodi A, Fessler JH, Parker C, Roth J (2001) Immunolocalization of UDP-glucose: glycoprotein glucosyltransferase indicates involvement of pre-Golgi intermediates in protein quality control. Proc Natl Acad Sci U S A 98:10710-10715 